\title{
Untargeted proteomics-based approach to investigate unintended changes in genetically modified maize used for food and feed purposes
}

\author{
Sarah Zanon Agapito-Tenfen ${ }^{*}$, Miguel Pedro Guerra ${ }^{2}$, Rubens Onofre Nodari², Odd-Gunnar \\ Wikmark $^{1}$ \\ 1 GenØk Centre for Biosafety, Siva innovasjonssenter Postboks 6418, 9294 Tromsø, Norway; \\ sarah.agapito@genok.no; odd-gunnar.wikmark@genok.no \\ 2 CropScience Department, Federal University of Santa Catarina, Florianópolis, Brazil; \\ miguel.guerra@ufsc.br; rubens.nodari@ufsc.br \\ *Correspondence: sarah.agapito@genok.no; ORCID 0000-0002-9773-0856
}

\begin{abstract}
Profiling technologies, such as proteomics, allow the simultaneous measurement and comparison of thousands of plant components without prior knowledge of their identity. The combination of these non-targeted methods facilitates a more comprehensive approach than targeted methods and thus provides additional opportunities to identify genotypic changes resulting from genetic modification, including new allergens or toxins. The purpose of this study was to investigate unintended changes in GM Bt maize grown in South Africa. In the present study, we used bi-dimensional gel electrophoresis based on fluorescence staining, coupled with mass spectrometry in order to compare the proteome of the field-grown transgenic hybrid (MON810) and its near-isogenic counterpart. Proteomic data showed that energy metabolism and redox homeostasis were unequally modulated in GM Bt and non-GM maize variety samples. In addition, a potential allergenic protein - pathogenesis related protein -1 has been identified in our sample set. These finding highlight the suitability of unbiased profiling approaches to complement current GMO risk assessment practices worldwide.
\end{abstract}

\section{Key-words}

Transgenic organisms; 2-D DIGE; profiling techniques; maize; allergenicity assessment. 


\section{Introduction}

Genetically modified organisms (GMOs) have been extensively grown and consumed in a number of countries since 1998. Twenty-years after the first cultivation, the accumulated genetically modified (GM) crop area surged to a record of 191.7 million hectares in 26 countries around the world (ISAAA, 2018). Despite the widespread use of GMOs, the need for biosafety science remains a concern and it is mandated in the domestic legislation of many countries as well as in international treaties (Davison 2010; Eckerstorfer et al. 2019).

Confidence in the safety and reliability of GMO food products depends significantly on the genetic integrity of the organism; however, the frequency of transformation-induced mutations which could result in altered metabolism, novel fusion proteins, or other pleiotropic effects leading to adverse effects are poorly understood (Zolla et al. 2008; Kohli et al. 2010; Brandão et al. 2010; Agapito-Tenfen et al. 2018). In fact, the transgene insertion site cannot be predetermined and for this reason transgenes may be inserted in functional genomic regions thus disrupting the structure and/or altering the regulation patterns of genes from the plant host genome as previously observed for some commercialized GM crops (Holck et al. 2002; Hernandez et al. 2003; Rosati et al. 2008; Morisset et al. 2009; La Paz et al. 2010). Other secondary unintended effects of genetic modification can also arise during conventional breeding as the result of hybridization or spontaneous mutations, processes that are integral to breeding programs (Van Gelder et al. 1991; Conner and Jacobs 1999 and FAO 2002). Other documented effect is related to the application of supporting technologies used in the GMO agroecosystem, such as the use of combined herbicides (Bøhn and Millstone, 2019).

Profiling technologies, such as proteomics, allow the simultaneous measurement and comparison of thousands of plant components without prior knowledge of their identity. The combination of these non-targeted methods facilitates a more comprehensive approach than targeted methods and thus provides additional opportunities to identify genotypic changes resulting from genetic modification, including new allergens or toxins (Ruebelt et al. 2006; Agapito-Tenfen et al. 2013). The identification of such changes in the GMO that could cause adverse effects on the conservation and sustainable use of biological diversity, taking also into account risks to human health, is a first step in the GMO risk assessment process (UNEP 2016).

Two-dimensional electrophoresis (2-DE) gel-based proteomic approaches have been widely used to investigate the protein-level metabolism of transgenic maize, soybean, cotton, rapeseed and rice in contrast to their non-transgenic counterpart in the past decade (Ren et al. 2009; Coll et al. 2011; Barbosa et al. 2012; Xue et al. 2012; Liu et al. 2015; Wang et al. 2015; Benevenuto et al. 2017; Galazzi et al. 2019). However, these studies do not report consistent results, which may be explained by their use of a variety of organism's genetic backgrounds and/or different growth conditions, as well as variations in the technologies applied (Ricroch et al. 2011). These inconsistencies highlight the importance of building a "database" of knowledge around genetic variability in GM crops, as well as the need for harmonization of analytical methods that could be addressed through continuous multi-laboratory tasks (Batista et al. 2010; Zanatta et al. 2020).

Among the different omics platforms investigating the proteome, 2-DE gel-based approaches enable the identification of protein isoforms that would not be possible by means of high throughput omics systems. In the present study, we used bi-dimensional gel electrophoresis based on fluorescence staining, coupled with mass spectrometry in 
order to compare the proteome of the field-grown transgenic hybrid (MON810) and its near-isogenic counterpart commercially available in South Africa. Protein profiles were generated and compared between the two plant varieties to assess differences in protein expression. Differentially expressed proteins were successfully identified and their molecular function and cellular components were analyzed. We observed imbalanced redox metabolism and a potential allergenic protein in GM maize expressing Bt toxin which have been grown in field conditions mimicking real world agricultural scenarios.

\section{Materials and Methods}

\section{Plant material and growing conditions}

The cultivation of GM maize MON810 event (unique identifier MON-ØØ81Ø-6, Monsanto Company), also known as Bt-maize, has been approved in South Africa in 1997 (CERA 2012). MON810 was genetically modified by particle bombardment to genomic insert the modified crylAb gene from Bacillus thuringiensis. The expression product of this gene is the insecticide protein (Bt toxin) Cry1 Ab. White maize variety PAN 6Q-321B containing MON810 event (Pannar Seed Ltda., South Africa) and its non-GM near isogenic variety PAN 6Q-121 (Pannar Seed Ltda., South Africa) were planted in November 2009. These are single-cross hybrid seeds which are the progeny derived from the cross of a maternal endogamous line "A" with the paternal endogamous line " $B$ ". This seed population is, therefore, highly genetically similar (all genotype should be AB).

After the confirmation of MON810 event in GM seeds and the absence in its near isogenic non-transgenic (non-GM) counterpart (data not shown), plants were grown side by side in $2.4 \mathrm{Ha}$ blocks (density of 20000 plants/ Ha) in the same field located at the University of Free State Research Farm, Bloemfontein, South Africa. Plots were managed following standard agricultural practices in the region, without the application of herbicides. No fungicide or insecticide was either applied.

Six plants were randomly sampled per maize hybrid from each plot inner rows, in order to avoid border effects. Maize leaves were collected at R1 stage (approximately 90 days after sowing). Sampling was performed during early morning in which around $5 \mathrm{~g}$ of material was collected from the third upper leaf, consisting of a $10 \mathrm{~cm}$ long tissue piece located in the mid portion. Plant samples were carefully checked for the absence of herbivory and disease symptoms, as well as necrotic tissue areas. The leaves were cut, placed in $15 \mathrm{ml}$ tubes before immersion in liquid nitrogen and transported to the lab. The samples were kept at $-80^{\circ} \mathrm{C}$ until used.

\section{Protein extraction and sample labeling for 2-D DIGE gel electrophoresis}

Each sample was separately ground-up in a mortar with liquid nitrogen and protein extraction was subsequently carried out according to Carpentier et al. (2005) with some modification. Phenol extraction and subsequent methanol/ammonium acetate precipitation was performed and PMSF was used as protease inhibitor. Pellets were resuspended in an urea/thiourea buffer compatible to DIGE (4\% w/v CHAPS, $5 \mathrm{mM}$ PMSF, $7 \mathrm{M}$ urea, $2 \mathrm{M}$ thiourea and $30 \mathrm{mM}$ Tris base; all reagents were purchased from SigmaAldrich Corporation, St. Louis, USA). Protein quantification was determined by means of the copper-based method 2-D Quant Kit (GE Healthcare Bio-Sciences AB, Uppsala, Sweden). A pool of $60 \mathrm{ug}$ of protein samples per variety (consisting of equal amounts of 
each of the six plants assessed per treatment) were labeled with $400 \mathrm{\rho mol} / \mathrm{ul}$ of CyDye DIGE fluors (GE Healthcare Bio-Sciences AB, Uppsala, Sweden), according to the manufacturer's instructions. Each pool was first separately labeled with a different fluor. After protein-fluor hybridization, samples were treated with lysine $(10 \mathrm{mM})$ to stop the reaction and then mixed together for 2-D DIGE gel electrophoresis separation.

\section{2-D DIGE gel electrophoresis conditions}

In order to determine the biological variance among our samples, a preliminary test has been carried out to established baseline variation information on samples collected for this study (Coll et al. 2011). The pre-test consisted of $450 \mathrm{ug}$ of each of the six unlabeled samples from each variety which were then separated by 2-D gels using Immobiline ${ }^{\mathrm{TM}}$ DryStrip gels of $13 \mathrm{~cm}$ and a linear $\mathrm{pH}$ range of 4-7 (GE Healthcare) coomassie brilliant blue G-250 colloidal stained gels (Candiano et al. 2004). 2-D gel electrophoresis conditions were performed as described by Weiss and Görg (2008).

Once determined that variability within samples were minimal and felt within the optimal range for proteomic analysis, the extracted proteins were separated by two-dimensional gel electrophoresis (Weiss and Görg 2008). In the isoelectric focusing (IEF) step, strip gels of $24 \mathrm{~cm}$ and a linear $\mathrm{pH}$ range of 4-7 (GE Healthcare) were used. Strips were initially rehydrated with labeled protein samples and a rehydration solution $(7 \mathrm{M}$ urea, $2 \mathrm{M}$ thiourea, $2 \%$ w/v CHAPS, $0.5 \%$ v/v IPG buffer (GE Healthcare), 0.002\% w/v bromophenol blue). Strips were then processed using an Ettan IPGPhor IEF system (GE Healthcare) in a total of 35000 Volts. $^{-1}$ and subsequently reduced and alkylated for 30 min under slow agitation in a Tris- $\mathrm{HCl}$ solution $(75 \mathrm{mM}), \mathrm{pH} 8.8$, containing $2 \% \mathrm{w} / \mathrm{v}$ $\mathrm{SDS}, 29.3 \% \mathrm{v} / \mathrm{v}$ glycerol, $6 \mathrm{M}$ urea, $1 \% \mathrm{w} / \mathrm{v} \mathrm{dtt}$ and $2.5 \% \mathrm{w} / \mathrm{v}$ iodocetamide. Strips were placed on top of SDS-PAGE gels (12\%, homogeneous) and used in the second dimension run with a Hoefer DALT system (GE Healthcare). Gels were immediately scanned with the FLA-9000 modular image scanner (Fujifilm Lifescience, Dusseldorf, Germany).

Preparative gels for each treatment were also performed in order to extract spots with statistical significance differential expression between varieties. These were performed with a $700 \mathrm{ug}$ load of total protein pools in $24 \mathrm{~cm}$ gels from each treatment, separately, and stained with coomassie (MS compatible) (Candiano et al. 2004).

\section{Gel analysis}

For the purpose of addressing plant-to-plant variability within our GM and non-GM varieties, the pre-test experiment consisted of twelve gels, six from each variety. These were analyzed all together by software Image Master 2D Platinum, version 7.0 (GE Healthcare). Gels were compared and matched spots volume of each gel was used to determine the biological variation by Principal Component Analysis (PCA) using Euclidean distance for quantitative analysis. PCA was first applied to determine the proportion of the total proteomic variation that originates from differences between biological repetitions. PCA analysis was performed by examining similarities of correlations between the observed measures. The analysis was carried out using covariance matrix performed by Multibase PCA PLS Cluster-Analysis Excel Add-in Program (Numerical Dynamics Co.). The 2-DIGE experiment consisted of four technical replicate gels, each containing a loading pool of six biological replicates per variety. Cross-comparisons among the different samples were performed using software Image 
Master 2D Platinum, version 7.0. Hierarchical matching of gels was organized in such a way that technical replicate gels were compared fist and exclusive spots were removed from subsequent analysis. To analyze gel similarities or experimental variations, such as disparities in stain intensity or sample loading, scatter plots based on a linear dependence between the spot values of one gel and the corresponding values in the reference gel were produced. Spots within each variety with a high coefficient of variance $(>20 \%)$ were excluded from the analysis. Therefore, only consistent spots for each variety were used in the comparative analysis. Statistical analyses were performed with the Student's $t$ test (95\% confidence interval).

\section{In-gel digestion and protein identification by MS/MS}

Gel spots were excised and subjected to in-gel reduction, alkylation, and tryptic digestion using 2-10 ng/ $\mu \mathrm{l}$ trypsin (V511A; Promega) (Shevchenko et al. 2006). These were analyzed by the Proteomics Platform at the Arctic University of Norway (UiT). Peptide mixtures containing $0.1 \%$ formic acid were loaded onto a nano ACQUITY Ultra Performance LC System (Waters Massachusetts, USA), containing a 5- $\mu$ m Symmetry C18 Trap column $(180 \mu \mathrm{m} \times 20 \mathrm{~mm}$; Waters $)$ in front of a 1.7- $\mu \mathrm{m}$ BEH130 C18 analytical column $(100 \mu \mathrm{m} \times 100 \mathrm{~mm}$; Waters). Peptides were separated with a gradient of 5-95\% acetonitrile, $0.1 \%$ formic acid, with a flow of $0.4 \mu \mathrm{l} / \mathrm{min}$ eluted to a Q-TOF Ultima mass spectrometer (Micromass; Waters). The samples were run in data dependent tandem MS mode. Peak lists were generated from MS/MS by the Protein Lynx Global server software (version 2.2; Waters). The resulting pkl files were searched against the NCBInr 2011120 protein sequence databases using Mascot MS/MS ion search (Matrix Sciences; http://matrixscience.com). The taxonomy used was Viridiplantae (Green Plants) and 'all entries' for contamination verification.

The following parameters were adopted for database searches: complete carbamidomethylation of cysteines and partial oxidation of methionines; peptide mass tolerance $\pm 100 \mathrm{ppm}$; fragment mass tolerance $\pm 0.1 \mathrm{Da}$; missed cleavages 1 ; and significance threshold level $(P<0.05)$ for Mascot scores $(-10 \log (P))$. Even though high Mascot scores are obtained with significant values, a combination of automated database searches and manual interpretation of peptide fragmentation spectra were used to validate protein assignments. Molecular functions and cellular components of proteins were compared against ExPASy Bioinformatics Resource Portal (Swiss Institute for Bioinformatics; http://expasy.org) and Gene Ontology Consortium (http:// geneontology.org). Genome location for each protein was searched against Maize Genome Sequencing Project (http://www.maizesequence.org/index.html) by using the protein name. A database search for allergenic epitopes was performed at the Allergen Database for Food Safety (ADFS; Division of Biochemistry and Immunochemistry of National Institute of Health Sciences; http://allergen.nihs.go.jp/ADFS/). A graphical abstract is presented in Figure 1. 


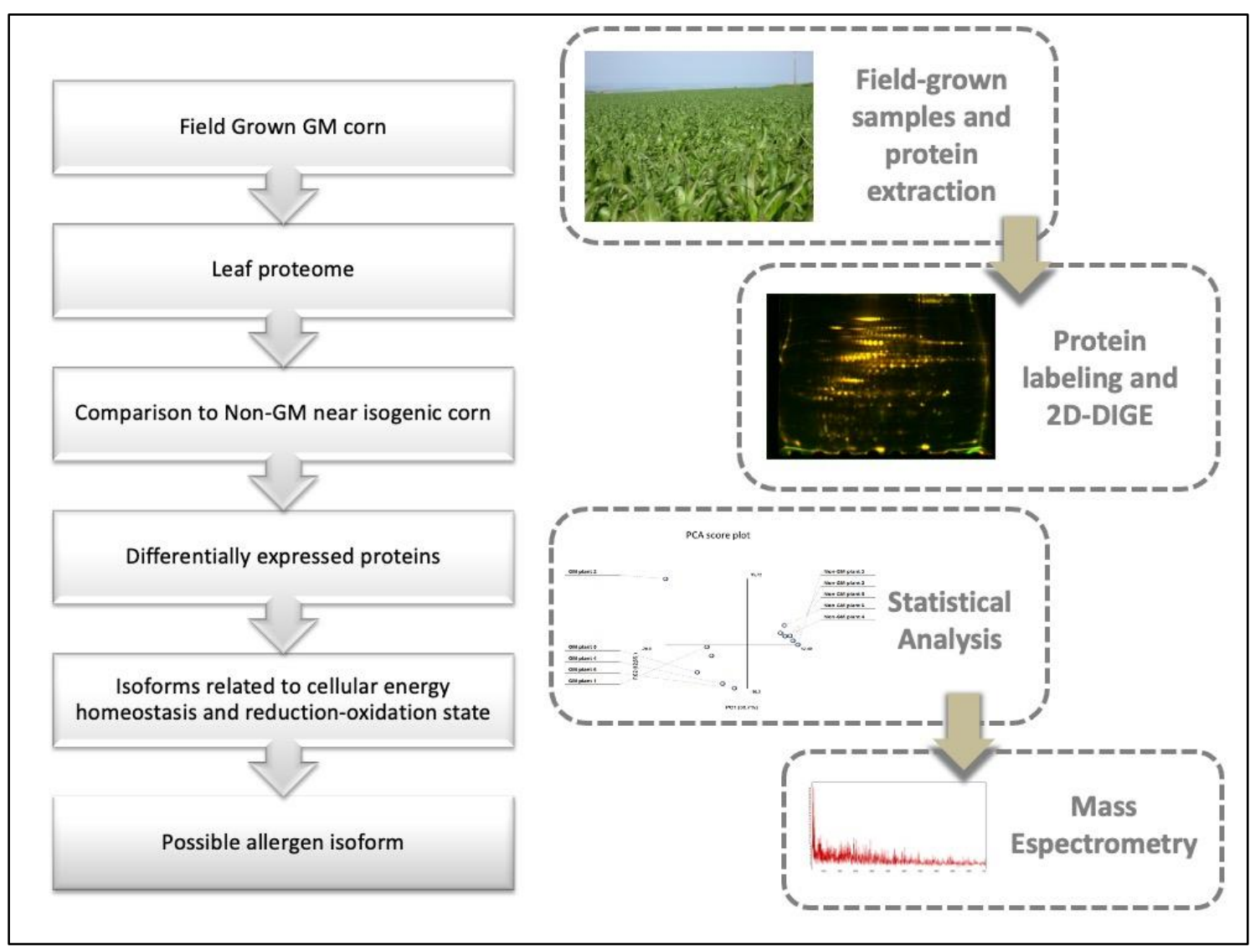

Figure 1: Graphical abstract and methodological pipeline for this study. Proteomic profiling analysis was performed for GM versus non-GM maize samples expressing the Cry $1 \mathrm{Ab}$ cassette. Plants were field grown in South Africa and subjected to a phenol-based protein extraction. 2-D fluorescent gels were analyzed and statistically significant spots $(<0.05 \%)$ were sequenced by MSMS analysis. Identified proteins were then searched against public databases for their annotations.

\section{Results and Discussion}

\section{Suitability and reproducibility of 2-D gel-based DIGE experiments}

Profiling techniques are broadly accepted as being capable of delivering sound descriptions of their target class of molecule in. a range of diverse field from molecular medicine to food safety and plant physiology studies (Karahalil B. 2016; Mehta et al. 2019; Argueso et al. 2019; Carrera et al. 2020). A number of molecular profiling studies have already indicated unintended effects of genetic modification (Coll et al. 2011; Wang et al. 2015; Peng et al. 2019; Zanatta et al. 2020). These studies revealed inter alia that compared to an effect of the genetic modification in the GM plants, there is also effects on the plant's physiology arising from (i) the genetic background, (ii) environmental conditions during growth, (iii) sampling procedures and (iv) plant-to-plant variability. Even the growth condition of the previous generation (such as the production of seeds) is known to cause epigenetic effects (Zolla et al. 2008).

Gel-free high-throughput mass spectrometry (MS) approaches have been applied in the past years to identify proteins on a larger scale with higher sensitivity compared to the traditional compositional analysis and reveal new aspects of the protein-level regulatory 
metabolism of GM crops (Garcia-Canas et al. 2011; Valdivel 2015). However, 2-DE technology is irreplaceable because it yields visualization maps of protein profiles, which provide information on the abundance of proteins and reliable evidence for existing protein isoforms (Benesova et al, 2012; Tan et al, 2017; Fonseca et al. 2012). Therefore, two-dimensional gel electrophoresis (2DE) is still one of the most important techniques, mostly due to its high performance regarding the separation of complex mixtures of fulllength proteins. Ultimately, gel-free and gel-based approaches are both of great value to a proteomic study and often provide complementary information for an overall richer analysis (Abdallah et al, 2012). Comparative proteomic analysis requires reliable methods for investigation of differential protein expression. An important source of variation is derived from technical artifacts or heterogeneities (i.e. differences between sample collection, IEFs, gel runs). Blocking enables an effective comparison between observed conditions with little dependence on technical heterogeneities thus improving the precision of the statistical analyses (Valledor and Jorin 2011). This approach has been successfully applied to reduce bias related to protein labeling in 2-D DIGE experiments.

In the present investigation, we have chosen the nearest isogenic counterpart as the appropriate comparator. This is in agreement with several international adopted guidelines for GMO safety analyses (Codex 2003; AHTEG 2011, EFSA 2011). In order to avoid environmental variation, we have performed a field experiment that consisted of several seed lines out of which individual plants were randomly selected from the inner rolls in order to minimize possible field effects derived from border effects or heterogeneities in the field area. For the purpose of addressing plant-to-plant variability within our treatment and control plants, we have performed PCA which demonstrated similarities in the protein quantity between different gels. PCA analytical report shows that the first three components explained $46 \%$ of the variation. The PCA plot showed a clear separation between the GM and non-GM plants in the first component, which explained $33.7 \%$ of the total variation (Figure 2). There was also biological variation in the analysis, explaining $12.6 \%$. These results show that the plant-to-plant variability fall in the range of what is usually accepted for proteomic analysis. 


\section{PCA score plot}

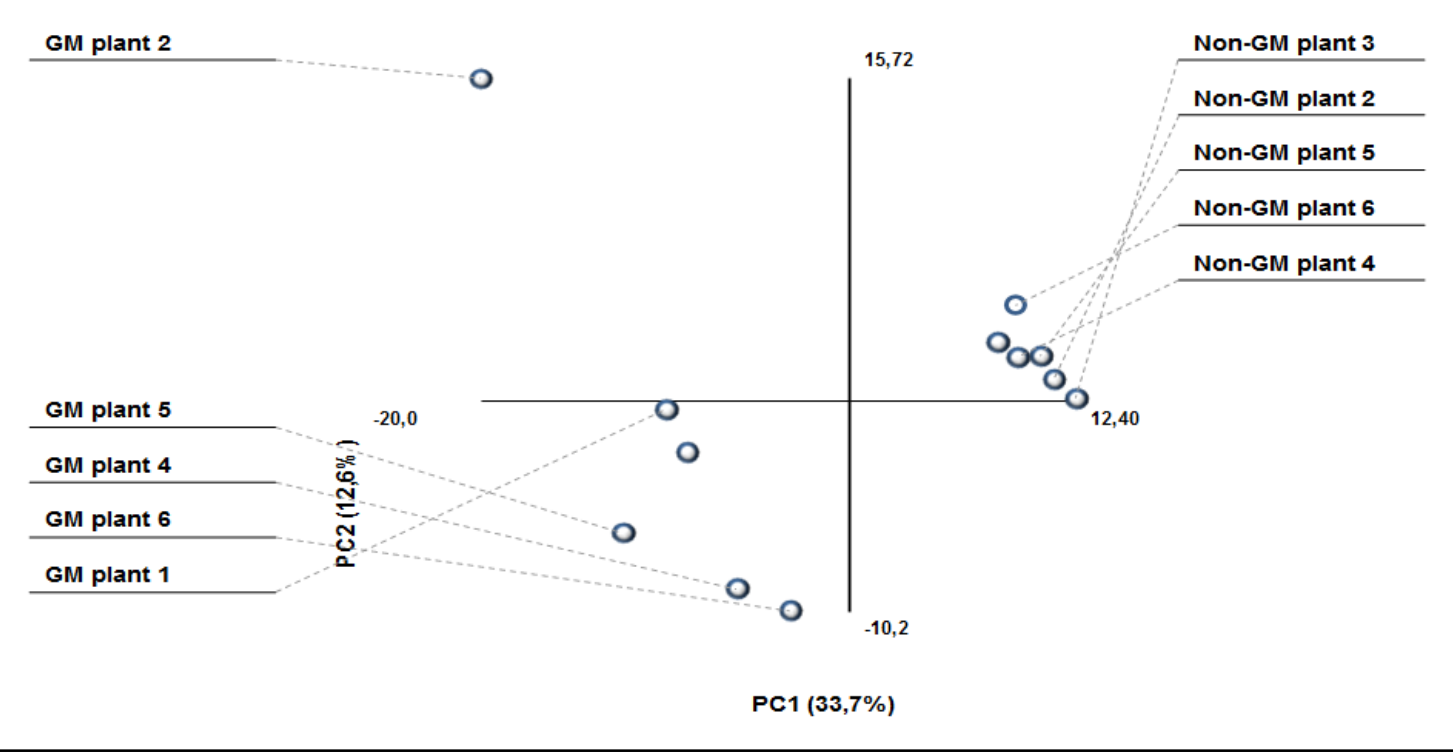

Figure 2: PCA score plots of 2-D proteomic data from transgenic (MON810 event) and non-transgenic near-isogenic maize plants (PAN 6Q-121) grown side-by-side under agricultural conditions at Bloemfontein, South Africa.

\section{Proteomic profile of white Bt-maize (MON810) and its non-GM counterpart}

In this study, 2-D DIGE combined with mass spectrometry (MS) was used to develop protein profiles in order to assess new protein products or metabolic differences occurring due to genetic modification resulting from particle bombardment. The proteomic profile of the field-grown white maize MON810 GM variety PAN 6Q-321B, widely grown in South Africa, was compared to its near-isogenic variety PAN 6Q-121; thus mimicking real world agricultural scenarios (Figure 3). 


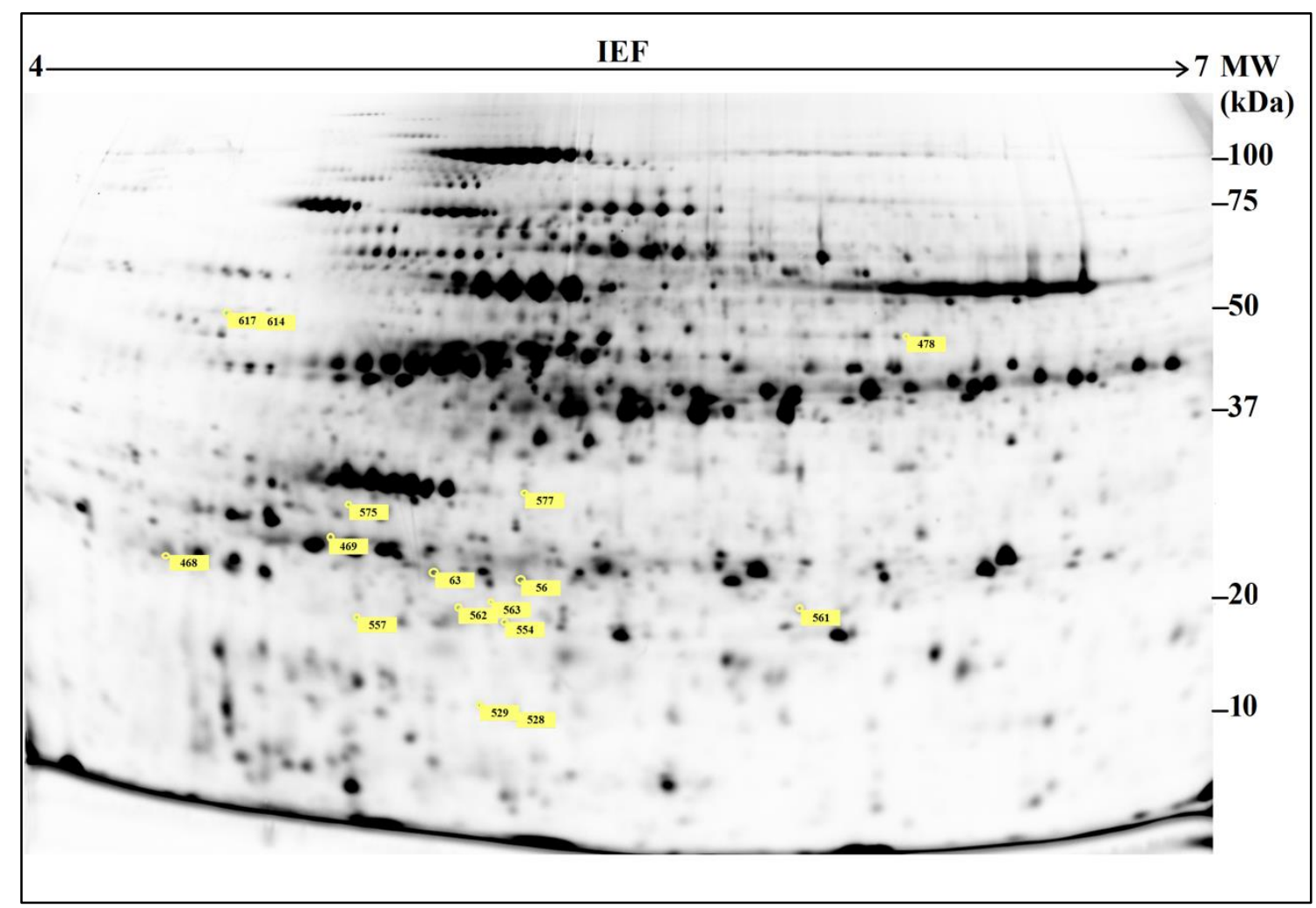

Figure 3: Representative two-dimensional difference gel electrophoresis (2-D DIGE) map of the proteome of genetically modified maize plants (MON810 event) between $\mathrm{pH} 4$ and 7. Delimited spots correspond to differentially expressed proteins selected for mass spectrometry identification. ID of identified proteins from Table 2 is indicated in yellow boxes.

The amounts of total protein extracted were $10.78 \pm 1.19 \mathrm{mg} / \mathrm{g}$ (dry weight) for the nonGM samples and $11.11 \pm 1.57 \mathrm{mg} / \mathrm{g}$ (dry weight) for the GM samples. Average numbers of spots on the 2-D DIGE gel were $710 \pm 105$ (GM) and $820 \pm 95$ (non-GM). The amount of protein extracted and the number of detected spots from both treatments did not show statistical significant difference $(P=0.749$ and 0.172 ; respectively). After manual verification of spots, gels were matched according to hierarchical condition, in which technical repetitions were first compared, followed by biological repetitions comparison and further treatment comparison. Therefore, gels from different treatments were internally matched and only consistent spots that were included in the analysis. The average correlation coefficients were $0.91 \pm 0.2$ for the non-GM sample and $0.92 \pm 0.2$ for the GM sample with a total number of matched spots of 514 and 669 for the non-GM and GM gels, respectively (Table 1). These results indicate a high degree of sensitivity and reproducibility using the 2D-DIGE/MS approach (Choudhary et al. 2020; De Campos et al. 2020). 
Table1. Total protein content, detected spots and matched spots of PAN 6Q-121 non-GM and PAN 6Q321B GM maize varieties grown under farm conditions in Bloemfontein, South-Africa. The number of differentially expressed spots from the comparison of both varieties is also presented.

\begin{tabular}{|c|c|c|c|c|c|}
\hline Variety & $\begin{array}{l}\text { Total protein } \\
\text { content (mg.g-1 } \\
\text { of dry weight) }\end{array}$ & $\begin{array}{l}\text { Average } \mathrm{n}^{\mathrm{o}} \\
\text { of spots } \\
\text { detected }^{\mathrm{a}}\end{array}$ & $\begin{array}{c}\mathrm{N}^{\circ} \text { of } \\
\text { matched } \\
\text { spots }\end{array}$ & $\begin{array}{l}\text { Exclusive spots } \\
(\text { match ID })^{b}\end{array}$ & $\begin{array}{c}\text { Differentially } \\
\text { expressed } \\
\text { spots (match } \\
\text { ID; fold of } \\
\text { variation) }^{\mathrm{b}} \\
\end{array}$ \\
\hline \multicolumn{6}{|l|}{ PAN 6Q- } \\
\hline 121 & $10.78 \pm 1.19$ & $710 \pm 105$ & 514 & $468 ; 469 ; 478$ & \\
\hline non-GM & & & & & $56(2)$ \\
\hline PAN 6Q- & & & & $528 ; 529 ; 554 ; 557$ & $63(1.5)$ \\
\hline $\begin{array}{c}321 \mathrm{~B} \\
\text { GM }\end{array}$ & $11.11 \pm 1.57$ & $820 \pm 95$ & 669 & $\begin{array}{l}561 ; 562 ; 563 ; 575 \\
577 \cdot 614 \cdot 617\end{array}$ & \\
\hline
\end{tabular}

a Values are means of $\mathrm{n}=4$ gels \pm standard deviation; ${ }^{\mathrm{b}}$ Spots were considered exclusive or differentially expressed when a Student's $t$ test results were significant (95\% confidence interval).

Differential protein expression patterns in MON810 compared to its near-isogenic line

A comparison between the GM and non-GM plants revealed a total of 16 different proteins that were either up or down regulated in one of the varieties at a statistically significant level $(P<0.05)$. Eleven out of 16 of the differentially expressed proteins were detectable only in the GM variety. And three proteins were completely repressed in the GM variety while 2 proteins were down-regulated by a factor of 1.5 and 2 (Figure 4 ). The 16 proteins were successfully identified with C.I.\% values greater than $95 \%$ using MALDI-TOF-MS/MS analysis $(P<0.05)$ (Table 2).
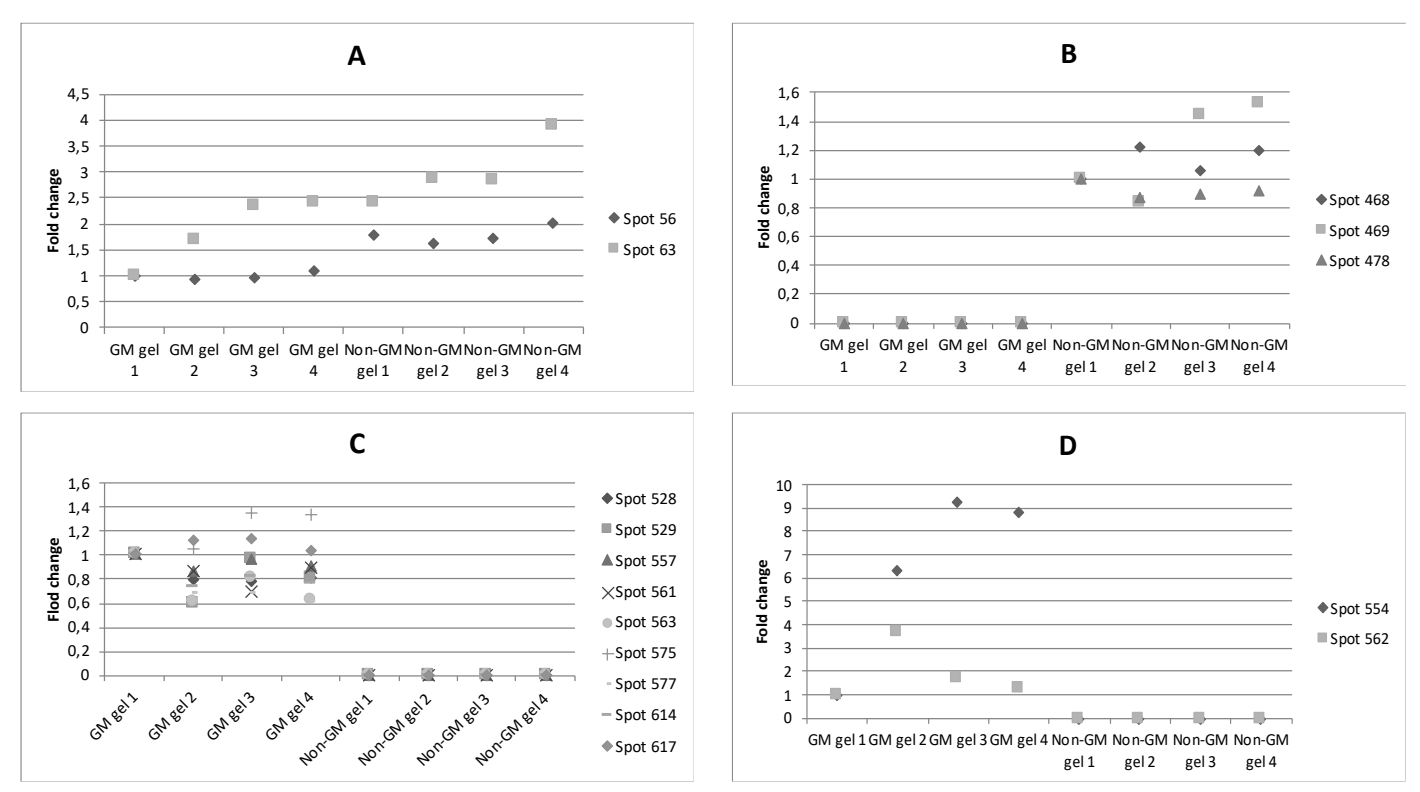

Figure 4: Histograms of fold-differences of proteins found to be significantly different (ANOVA, $\mathrm{P}<0.05$ ) in leaf samples of genetically modified maize (MON810 event) and non-transgenic near isogenic (PAN 6Q-121) field-grown in Bloemfontein (South Africa; autumn 2009). Sixteen proteins out of an average of 765 spots presented a significant difference in abundance; in which two were down regulated (A), three were repressed (B) and 11 were only expressed in the GM plants (C and D). Spots 554 and 562 had greater 
values and were, therefore, included in a new histogram. Protein expression levels represent the relative protein expression compared to a reference gel (four technical replicates were used).

Most proteins were specific enzymes closely related to cellular energy homeostasis and reduction-oxidation (redox) metabolism (Figure 5). We found proteins involved in photosynthesis and the synthesis of temporary storage polysaccharide pathways, including adenylate kinase (down-regulated in the GM), bifunctional 3phosphoadenosine 5-phosphosulfate synthetase (repressed in the GM), thylakoid lumenal $19 \mathrm{kDa}$ protein (expressed in the GM), chlorophyll a-b binding protein 6A (expressed in the GM), all identified in Zea mays species; plus chloroplast fructose-1,6-bisphosphatase (expressed in the GM) identified in Oryza sativa Indica Group. Previously, it has been also observed energy-related proteins, such as those involved in the photophosphorylation metabolism (ferredoxin-nadp reductase and thylakoid lumenal $19 \mathrm{kda}$ proteinin) for $\mathrm{Bt}$ maize grown in field conditions in Brazil (Agapito-Tenfen et al. 2011). Few other studies have also investigated the proteome or the transcriptome profile of GM Bt maize (MON810 event) but the functional information on the identified differential proteins and genes were not available; most likely due to the lack of annotations in databases at the time of publication (Coll et al. 2010; Vaclavik et al. 2013; Balsamo et al. 2015).

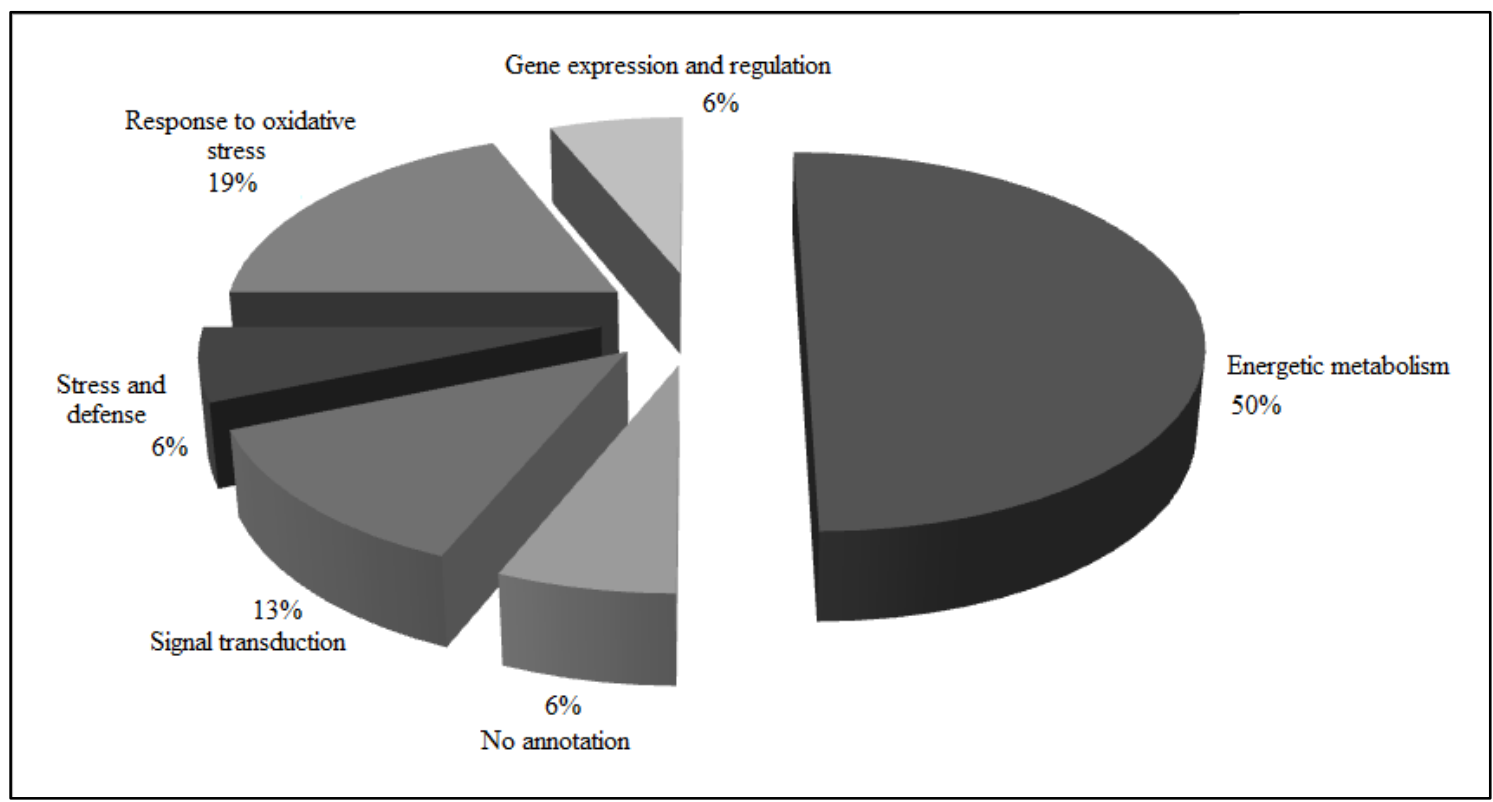

Figure 5: Pie chart distribution of differentially expressed proteins (ANOVA, P <0.05) between leaf samples of genetically modified maize (MON810 event) and non-transgenic isogenic (PAN 6Q-121) based on the function of the proteins. Protein functions were predicted according to Gene Ontology terms. Note: $\mathrm{N}=16$.

Table 2. MS/MS Identification of the Differentially Expressed Proteins in PAN 6Q321B GM versus PAN 6Q-121 non-GM maize varieties. 
We have also observed the cytochrome c oxidase subunit II (over expressed in GM) which is involved in the aerobic respiration, 2-cys peroxiredoxin BAS1 (repressed in the GM) which catalyzes the transfer of electrons from sulfhydryl residues to peroxides, and the manganese superoxide dismutase enzyme (SOD-3) (expressed in the GM). Superoxide dismutase enzymes (SODs) act as antioxidants and protect cellular components from being oxidized by reactive oxygen species (ROS). ROS can form as a result of various stress conditions, such as drought, injury, pesticides, ozone, plant metabolic activity, nutrient deficiencies, photoinhibition, air and soil temperature, toxic metals, and UV or gamma rays. Therefore, these are important enzymes that are closely linked to stress perception and physiological responses to stress.

Disturbances at the redox metabolism of transgenic Bt maize have been previously observed for GM maize lines expressing crylAb/cry2Aj transgenes (Hao et al. 2017). Field grown Bt maize also showed a different proteomic profile for other anti-oxidant enzimes, including the 2-cys peroxiredoxin and apx1 - cytosolic ascorbate peroxidase (Agapito-Tenfen et al. 2011).

In addition, we found isoforms for five identified proteins (Table 2). These isoforms are photosynthesis-related proteins present in the chloroplast and some with specific functions in phosphoric ester hydrolase activity, calcium ion binding and oxidoreductase activity.

Although protein identity matches were highly confident, we observed differences between theoretical and expected molecular weight and $p I$. Similarly, when analyzing GM maize seed lines, Zolla et al. (2008) found that a number of seed storage proteins (such as globulins and vicilin-like embryo storage proteins) exhibited truncated forms with a molecular mass significantly lower than native ones. Our results also showed lower molecular weight for photosynthesis-related, signal transduction and pathogenesisrelated proteins. As for $p I$ changes, most of our identified proteins showed lower $p I$ than the theoretical values. Considering that we have high resolution gels with little or no smear, and the protein identity match is high confident, the low $p I$ values may be evidence of a post-translational modification, cleavage or alternative-splicing event.

Moreover, no transgenic protein products (Cry1 Ab) deriving from the transgene inserted into MON810 event were revealed in our 2-D DIGE gels. We hypothesized that the extraction buffer at $\mathrm{pH} 8.0$ does not allow Cry1 Ab solubilization, which is well known to be solubilized around pH 11 (Zolla et al. 2008; Balsamo et al. 2011).

Genes are not randomly distributed in the genome and their coordinated expression can be regulated by many factors at virtually any step of gene expression; from transcriptional initiation, to RNA processing, and to the post-translational modification of a protein. Nevertheless, in the case of a transgenic organism, the insertion and expression of a transgene can also be a source of endogenous gene modulation (Latchman 2005). Similarly, different copies of the introduced gene which integrate into the host chromosomes at different positions are expressed at very different levels, suggesting that gene activity is being influenced by adjacent chromosomal regions (Li et al. 1999). We have included the genome location of each of the differentially expressed protein found in this study to our analysis (Table 2). Interestingly, the genome location of differentially expressed genes varied, thus showing the influence of MON810 transgene integration site, into other genomic locations, likely due to changes in chromatin structure (e.g., 
heterochromatin) or inserted sequences acting as transcriptional regulation elements (e.g., enhancers, strong promoters) (Weising et al. 1988).

Independent researchers have sequenced flanking regions at both ends and found results that matched to sequences in different chromosomes. Holck et al. (2002) found that the maize endogenous DNA showed high similarity, $88 \%$ across the 440 bp next to the 5' end junction, with the Zea mays chromosome $422 \mathrm{kD}$ alpha zein-gene cluster region (accession number AF105716). And Rosati et al. (2008) found 99\% identity of the junction 3' end with the chromosome 5 BAC clone ZMMBBc0409B05 (accession number AC185641). The latter having $82 \%$ identity with Oryza sativa locus coding for a putative HECT E3 ubiquitin ligase. These results suggest that the integration of the MON810 vector has probably caused a complex recombination event as the 5' e 3 ' end regions do not correspond to the same genomic locus.

We identified six proteins that were located in chromosomes 4 and 5 - the putstive location of MON810 insert. Other proteins were found to be located at all maize chromosomes, with the exception of chromosome 7, 10 and circular chloroplast chromosome. Apparently, these genes are not clustered together but dispersed in the maize genome. And their expression does not seem to be controlled by a common regulatory process. These should, however, be further investigated.

\section{The allergenic potential of the protein isoform in white Bt-maize}

We found an unique spot (Match ID 529) corresponding to the pathogenesis-related protein class 1 (PR1) was expressed only in the GM variety. Annotations for this protein in the ExPASy Tool related it to a 160 amino acid residues protein with a $17.1 \mathrm{kDa}$ mass and belonging to the Bet v-1family of proteins. The betallergens have a signature represented by a 7-element fingerprint which was derived from an initial alignment of motifs that were drawn from short conserved regions spanning the full alignment length of 45 sequences (Attwood et al. 2013). Zea mays PR1 has not been experimentally characterized, but it is $85.7 \%$ identical in amino acid sequence to the well characterized PR1 from Sorghum bicolor (Q41298_SORBI).

Epitope search in the allergen database for food safety (http://allergen.nihs.go.jp) using Z. mays PR1 as the query, revealed high matches to two known allergens: PR1 from Asparagus officinalis and Pru av1 from Prunus avium. A. officinalis PR1 was a 51\% identity match with $Z$. mays PR1 and $P$. avium AV1 was a $42.4 \%$ match (Table 3 ). The Allergen Database for Food Safety is based on a Joint FAO/WHO Expert Consultation on Foods Derived from Biotechnology report which proposed that cross-reactivity between a query protein and a known allergen has to be considered when there is more than $35 \%$ identity match in the amino acid sequence of the expressed protein, using a window of either 80 amino acids and a suitable gap penalty or the identity of 6 contiguous amino acids. The epitope search results in relation to PR1 from A. officinalis, produced a score of $173,51 \%$ identity and an E-Value $=1 \mathrm{e}-42$. The search result related to the prediction of allergenicity produced a match with Pru av1 from $P$. avium with a score of 481.4, 42.4\% identity and an E-Value $=4.8 \mathrm{e}-22$. Spangfort et al. (2003) studied IgEbinding epitope of Bet v-1 from Betula sp. and verified that the epitope occupies $10 \%$ of the molecular surface area of the protein. These authors found that it is clearly conformational and has a sequential motif around residues 42-52. Our results show a full match with the same sequential motif (43 -50 residues) for the Pru av1 data. Further, our 
peptide sequence obtained from the MS/MS results produced a true match to the epitope region.

The allergenic potential of the Bet v-1 like protein, to which the PR proteins are related, are common pollen and plant food allergens that have been widely described, including their possible isoforms (Reuter et al. 2005). In a recent review, Schenk et al. (2010) show evidence of variation in the immune reaction to different isoforms of Bet $\mathrm{v}-1$ allergens as the allergenicity of pollen from a particular biological source is not determined by the total allergen content alone, but also by the quantities of the different isoforms and their allergenic potential. To the best of our knowledge, there is no investigation on transgenic maize leaf allergens reported in the literature.

A recent study reveals differential reactivity of plasma from two maize allergic subjects against transgenic (MON810) versus non-transgenic grain protein extracts; however, it was not possible to identify the putative allergens (Fonseca et al. 2012). Although the authors were not able to observe differential expression for the tested allergen genes presented in GM versus non-GM varieties, these authors have confirmed the reactivity of chitinase and endochitinase A proteins in maize samples, both belonging to the group of the "pathogenesis-related proteins".

Nonetheless, the potential allergen isoform identified in this study (PR1) shows high homology to the major cherry allergen (Pru av1) and 97 of 101 (96\%) patients with birch pollinosis and oral allergy syndrom to cherry had IgE against Pru av 1 (Scheuer et al. 2001). It is, therefore, highly recommended that further studies should be performed in order to investigate the expression of PR1 and its allergenic potential.

Coll et al. (2009) investigated field-grown maize leaves at the vegetative two-leaf (V2) and the tasseling (VT) stages and compared those results to the previous study with the same varieties at V2 stage under in vitro conditions by transcriptomics. These authors found four transcripts out of 36 that were differentially expressed between GM (MON810 event) and its conventional counterpart. These were identified as pathogenesis related protein (PR-9), trypsin inhibitor gene, Myb-like protein E1 and one uncharacterized RNA-binding protein. It is interesting to note that PR-9 was overexpressed in the GM plants in all stages and conditions analyzed, but the fold variation was greater for V2 plants grown under field-conditions. PR-9 and PR-10 represent two protein classes, the first being a peroxidase-like and the second a ribonuclease-like protein. Although these proteins participate in different metabolic pathways, both are produced in plants in the event of a pathogen attack. The distinct expression level between GM and non-GM plants reveals that the presence of an insecticide protein $(\mathrm{Bt})$ might challenge plant-pathogen response differentially. Evidence to support this idea has been observed by Coll et al. (2011) study, which has investigated the proteome of GM maize grains grown under field conditions. Coll et al. (2011) found 4 and 6 differentially expressed proteins in 2 different commercialized maize hybrids in Spain. These authors concluded that the differential expression was variety-specific manner and called attention to the fact that depending on the experimental conditions applied, the analysis concerned a defined window in terms of $\mathrm{pI}$ and MW and are restricted to soluble and abundant proteins.

In principle, it is possible that the allergenic potential of GMOs may be increased due to the introduction of potential foreign allergens, to potentially upregulated expression of allergenic components caused by the modification of the wild type organism or to different means of exposure. It is suggested for GMO risk analysis that experimental comparison of the wild-type organism with the whole GMO regarding their potential to 
elicit reactions in allergic individuals and to induce de novo sensitizations should be investigated along with the current evaluation of physiochemical properties and sequence homology with known allergens (Spok et al. 2005).

Therefore, we strongly suggest that further studies should be performed in order to investigate the nature and the allergenic potential of the PR1 protein isoform found in our study.

Relevance of the use of profiling-techniques in comparative risk assessments and contributions to the method development

Proteomics and the use of bi-dimensional gel electrophoresis have long being tested as analytical tools that can complement existing risk assessment methods. Bi-dimensional gels have the capacity of characterizing and distinguishing varieties and genotypes, identifying possible allergens present in a sample, and detecting possible posttranslational modifications (Zolla et al. 2008).

Other studies have revealed that transgenic plants react differently to environmental conditions as compared to their near isogenic counterparts. In these studies, differences in gene expression, both proteins and metabolites, are not a product of the transgene per $s e$. The differently expressed products are affected by the genetic manipulation where the process of transformation seems to cause insertional or pleiotropic changes in the maize proteome. Several other studies have investigated the proteome of transgenic maize grains due to concerns about human and animal consumption. However, when released into the environment, humans and animals are in contact with the GMO by several different exposure routes which is not always related to grains alone. In addition, at the hazard identification step, any genotypic and phenotypic differences in the GMO should be scrutinized for their potential safety effect. According to the Guidance on Risk Assessment of Living Modified Organisms (AHTEG 2011), the "exposure assessment" aims to determine whether the receiving environment will be exposed to an living modified organism (LMO) that has the potential to cause adverse effects, taking into consideration the intended transfer, handling and use of the LMO, and the expression level, dose and environmental fate of transgene products.

In our study, field-grown maize was sampled in order to investigate the proteome of maize leaves under real field conditions. Therefore, our approach provides an important insight into environmental risk assessments (ERA) with regards to possible impacts on herbivores and/or other pathogen communities that feed on the transgenic maize leaf.

Current ERA practice of GM maize for food and feed or cultivation purposes in the European Union have been challenged due to the assumption that GM plants consist of two parts that function in a linear additive fashion: the crop and the novel GM transgene product (Dolezel et al. 2011). This is assumption is based on the substantial equivalence concept; when no statistically relevant compositional changes are detected, the crop plant is declared as safe and consequently only the added transgene product is subject to testing in the environmental risk assessment.

It is important to note that our findings might be specific to the sample used, especially because these proteins are highly environmentally dependent. Therefore, case-by-case studies should be performed in order to provide reliable results for a specific type of risk assessment. The detection of changes in protein profiles does not present a safety issue per se; however, further studies should be conducted in order to address the biological 
relevance of such changes. Finally, regulatory agencies may take into account proteomic studies among the required ones.

\section{Conclusions}

In conclusion, our results showed that GM Bt maize grown in South Africa were clustered together and distant from on-GM genotypes analyzed by PCA which explained cerca $34 \%$ of the variation in the dataset. In addition, we obtained evidence of possible synergistic and antagonistic interactions following Bt transgene insertion into the GM maize genome. This conclusion is based on the observation of several metabolic processes that were disturbed in the GM samples alone. These proteins were mainly assigned to the energy/carbohydrate metabolism and also found in previous studies. In addition, a potential allergenic protein PR1 was also observed in the GM Bt samples, in which the epitope has been sequenced by MSMS. Such observations indicate that the genome changes in Bt GM maize may influence the overall gene expression in ways that may have relevance for hazard identification assessments.

\section{Author Contributions}

Conceptualization- O.W. and S.Z.A; Data curation- S.Z.A; Formal analysis-O.W. and S.Z.A.; Funding acquisition- O.W., M.P.G. and R.O.N.; Investigation-O.W., S.Z.A., M.P.G and R.O.N.; Methodology-O.W. and S.Z.A.; Project administrationO.W; Resources-O.W., M.P.G and R.O.N; Supervision-O.W.; Validation-S.Z.A.; Writing — original draft, S.Z.A; Writing - review and editing, O.W., M.P.G, R.O.N and S.Z.A. All authors have read and agreed to the published version of the manuscript.

\section{Funding}

This work, including experimental design, sample collection, data analysis and interpretation, and manuscript writing, were supported by the Environmental Biosafety Cooperation Project between South Africa and Norway coordinated by the South African National Biodiversity Institute. CAPES and CNPq provided for scholarships to S.Z.A., M.P.G. and R.O.N.

\section{Acknowledgments}

The authors would like to thank the Center of Structural Molecular Biology (CEBIME/UFSC, Prof. Hernan Terenzi), at which part of the work was developed. This was also a joint project between UFSC and GenØk.

\section{Conflicts of Interest}

The authors declare no conflict of interest.

\section{References}


AHTEG, Guidance Document on Risk Assessment of Living Modified Organisms, http://www.cbd.int/doc/meetings/bs/mop-06/official/mop-06-13-add1-en.pdf, United Nations Environment Programme Convention for Biodiversity, 2011.

Argueso, CT, Assmann, SM, Birnbaum, KD, et al. Directions for research and training in plant omics: Big Questions and Big Data. Plant Direct. 2019; 3: 1- 16. https://doi.org/10.1002/pld3.133

Attwood TK, Bradley P, Flower DR, et al. PRINTS and its automatic supplement, prePRINTS. Nucleic Acids Res. 2003;31(1):400-402. doi:10.1093/nar/gkg030

Balsamo GM, Cangahuala-Inocente GC, Bertoldo JB, Terenzi H, Arisi AC. Proteomic analysis of four Brazilian MON810 maize varieties and their four non-geneticallymodified isogenic varieties. J Agric Food Chem. 2011;59(21):11553-11559. doi:10.1021/jf202635r

Barros E, Lezar S, Anttonen MJ, van Dijk JP, Röhlig RM, Kok EJ, Engel KH. Comparison of two GM maize varieties with a near-isogenic non-GM variety using transcriptomics, proteomics and metabolomics. Plant Biotechnol J. 2010 May 1;8(4):43651. doi: 10.1111/j.1467-7652.2009.00487.x.

Batista R, Oliveira M. Plant natural variability may affect safety assessment data. Regul Toxicol Pharmacol. 2010;58(3 Suppl):S8-S12. doi:10.1016/j.yrtph.2010.08.019

Candiano G, Bruschi M, Musante L, et al. Blue silver: a very sensitive colloidal Coomassie G-250 staining for proteome analysis. Electrophoresis. 2004;25(9):13271333. doi:10.1002/elps.200305844

Carpentier SC, Witters E, Laukens K, Deckers P, Swennen R, Panis B. Preparation of protein extracts from recalcitrant plant tissues: an evaluation of different methods for twodimensional gel electrophoresis analysis. Proteomics. 2005;5(10):2497-2507. doi:10.1002/pmic.200401222

CERA, GM Crop Database Center for Environmental Risk Assessment (CERA), ILSI Research Foundation, Washington D.C, 2012.

Choudhary MK, Nomura Y, Shi H, Nakagami H, Somers DE. Circadian Profiling of the Arabidopsis Proteome Using 2D-DIGE. Front Plant Sci. 2016 Jul 12;7:1007. doi: 10.3389/fpls.2016.01007.

Codex, The Guideline for The Conduct of Food Safety Assessment of Foods Derived from Recombinant-DNA Plants - CAC/GL 45-2003, Codex Alimentarius Commission, 2003.

Coll A, Nadal A, Collado R, et al. Natural variation explains most transcriptomic changes among maize plants of MON810 and comparable non-GM varieties subjected to two Nfertilization farming practices. Plant Mol Biol. 2010;73(3):349-362. doi:10.1007/s11103010-9624-5

Coll A, Nadal A, Rossignol M, Puigdomènech P, Pla M. Proteomic analysis of MON810 and comparable non-GM maize varieties grown in agricultural fields. Transgenic Res. 2011;20(4):939-949. doi:10.1007/s11248-010-9453-y

Conner, A. J.; Jacobs, J. M. Genetic engineering of crops as potential source of genetic hazard in the human diet. Mutat. Res. 1999, 443, 223-234. 
DavisonJ. GM plants: Science, politics and EC regulations, Plant Science. 2010, 178:9498.

de Campos BK, Galazzi RM, Dos Santos BM, Balbuena TS, Dos Santos FN, Mokochinski JB, Eberlin MN, Arruda MAZ. Comparison of generational effect on proteins and metabolites in non-transgenic and transgenic soybean seeds through the insertion of the cp4-EPSPS gene assessed by omics-based platforms. Ecotoxicol Environ Saf. 2020 Oct 1;202:110918. doi: 10.1016/j.ecoenv.2020.110918.

Dolezel M, Miklau M, Hilbeck A, Otto M, Eckerstorfer M, Heissenberger A, Tappeser B, Gaugitsch H. Scrutinizing the current practice of the environmental risk assessment of GM Maize applications for cultivation in the EU. Env Sci Eur. 2011;23:33. https://doi.org/10.1186/2190-4715-23-33

EFSA, Scientific Opinion on Guidance on selection of comparators for the risk assessment of genetically modified plants and derived food and feed, EFSA Journal 9 (2011) 2149.

FAO/WHO. Report of the Third Session Of the Codex ad hoc Intergovernmental Task Force on Foods Derived from Biotechnology, Yokohama, Japan; Codex Alimentarius Commission, FAO: Rome, 2002.

Fonseca C, Planchon S, Renaut J, Oliveira MM, Batista R. Characterization of maize allergens - MON810 vs. its non-transgenic counterpart. J Proteomics. 2012;75(7):20272037. doi:10.1016/j.jprot.2012.01.005

G.M. Balsamo, G.C. Cangahuala-Inocente, J.B. Bertoldo, H. Terenzi, A.C.M. Arisi, Proteomic analysis of four brazilian MON810 maize varieties and their four nongenetically-modified isogenic varieties, J. Agric. Food Chem. 59 (2011) 11553-59.

Hernández M, Pla M, Esteve T, Prat S, Puigdomènech P, Ferrando A. A specific realtime quantitative PCR detection system for event MON810 in maize YieldGard based on the 3'-transgene integration sequence. Transgenic Res. 2003;12(2):179-189. doi:10.1023/a:1022979624333

HolckAL, Vaïtilingom M, Didierjean L, Rudi K. 5' -nuclease PCR for quantitative event specific detection of the genetically modified Mon810 MaisGard (TM) maize. Eur. Food Res. Technol. 2002; 214:449-53.

ISAAA. 2017. Global Status of Commercialized Biotech/GM Crops in 2017: Biotech Crop Adoption Surges as Economic Benefits Accumulate in 22 Years. ISAAA Brief No. 53. ISAAA: Ithaca, NY.

Karahalil B. Overview of Systems Biology and Omics Technologies. Curr Med Chem. 2016;23(37):4221-4230. doi: 10.2174/0929867323666160926150617.

Kohli A, Miro B, Twyman RM. Transgene integration, expression and stability in plants: Strategies for imporvements. In: Kole C, Michler C, Abbott AG, Hall TC, editors. Transgenic Crop Plants. Heidelberg: Springer; 2010. p. 201-238.

La Paz JL, Pla M, Papazova N, Puigdomènech P, Vicient CM. Stability of the MON 810 transgene in maize. Plant Mol Biol. 2010;74(6):563-571. doi:10.1007/s11103-010-96962

Latchman DS. Gene regulation: a eukaryotic perspective, fifth ed., Taylor \& Francis Group, New York, 2005. 
Li Q, Harju S, Peterson KR. Locus control regions: coming of age at a decade plus. Trends Genet. 1999;15(10):403-408. doi:10.1016/s0168-9525(99)01780-1

Mehta S., James D., Reddy M.K. (2019) Omics Technologies for Abiotic Stress Tolerance in Plants: Current Status and Prospects. In: Wani S. (eds) Recent Approaches in Omics for Plant Resilience to Climate Change. Springer, Cham. https://doi.org/10.1007/978-3-030-21687-0_1

Morisset D, Demsar T, Gruden K, Vojvoda J, Stebih D, Zel J. Detection of genetically modified organisms--closing the gaps. Nat Biotechnol. 2009;27(8):700-701. doi:10.1038/nbt0809-700

Nielsen KM. Biosafety data as confidential business information. PLoS Biol. 2013;11(3):e1001499. doi:10.1371/journal.pbio.1001499

Numerical Dynamics, Multibase: Excel Add-ins for PCA and PLS, version 2013, 2013.

Reuter A, Fortunato D, Garoffo LP, et al. Novel isoforms of Pru av 1 with diverging immunoglobulin $\mathrm{E}$ binding properties identified by a synergistic combination of molecular biology and proteomics. Proteomics. 2005;5(1):282-289. doi:10.1002/pmic.200400874

Ricroch AE, Bergé JB, Kuntz M. Evaluation of genetically engineered crops using transcriptomic, proteomic, and metabolomic profiling techniques. Plant Physiol. 2011;155(4):1752-1761. doi:10.1104/pp.111.173609

Rosati A, Bogani P, Santarlasci A, Buiatti M. Characterisation of 3' transgene insertion site and derived mRNAs in MON810 YieldGard maize. Plant Mol Biol. 2008;67(3):271281. doi:10.1007/s11103-008-9315-7

Ruebelt MC, Leimgruber NK, Lipp M, et al. Application of two-dimensional gel electrophoresis to interrogate alterations in the proteome of genetically modified crops. 1. Assessing analytical validation. J Agric Food Chem. 2006;54(6):2154-2161. doi:10.1021/jf0523566

Schenk MF, Gilissen LJ, Smulders RJ, America TH. Mass spectrometry and pollen allergies. Expert Rev Proteomics. 2010;7(5):627-630. doi:10.1586/epr.10.32

Scheurer S, Pastorello EA, Wangorsch A, Kästner M, Haustein D, Vieths S. Recombinant allergens Pru av 1 and Pru av 4 and a newly identified lipid transfer protein in the in vitro diagnosis of cherry allergy. J Allergy Clin Immunol. 2001;107(4):724-731. doi:10.1067/mai.2001.113864

Shevchenko A, Wilm M, Vorm O, Mann M. Mass spectrometric sequencing of proteins silver-stained polyacrylamide gels. Anal Chem. 1996;68(5):850-858. doi:10.1021/ac950914h

Spangfort MD, Mirza O, Ipsen H, Van Neerven RJ, Gajhede M, Larsen JN. Dominating IgE-binding epitope of Bet $\mathrm{v}$ 1, the major allergen of birch pollen, characterized by X-ray crystallography and site-directed mutagenesis. J Immunol. 2003;171(6):3084-3090. doi:10.4049/jimmunol.171.6.3084

Spök A, Gaugitsch H, Laffer S, et al. Suggestions for the assessment of the allergenic potential of genetically modified organisms. Int Arch Allergy Immunol. 2005;137(2):167-180. doi:10.1159/000086315 
Valledor L, Jorrín J. Back to the basics: Maximizing the information obtained by quantitative two dimensional gel electrophoresis analyses by an appropriate experimental design and statistical analyses. J Proteomics. 2011;74(1):1-18. doi:10.1016/j.jprot.2010.07.007

van Gelder, W. M. J.; Scheffer, J. J. C. Transmission of steroidal glycoalkaloids from Solanum Vernei to the cultivated potato. Phytochemistry 1991, 30, 165-168.

Walker K, Frederick R. Entomological Risks of Genetically Engineered Crops. In: Editorin-Chief: Jerome O. Nriagu, Editor(s)-in-Chief, Encyclopedia of Environmental Health, Elsevier, Burlington, 2011, pp. 306-314.

Weising K, Schell J, Kahl G. Foreign Genes in Plants. Ann. Rev. Genet. 1988; 22:42177.

Weiss W, Gorg A. Sample solubilization buffers for two-dimensional electrophoresis, in.: Posch, A (Eds.), Methods in Molecular Biology-2D PAGE: Sample Preparation and Fractionation, A. Humana Press, New Jersey, 2008, pp. 35-42.

Zolla L, Rinalducci S, Antonioli P, Righetti PG. Proteomics as a complementary tool for identifying unintended side effects occurring in transgenic maize seeds as a result of genetic modifications. J Proteome Res. 2008;7(5):1850-1861. doi:10.1021/pr0705082 
Table 2. MS/MS Identification of the Differentially Expressed Proteins in PAN 6Q-321B GM versus PAN 6Q-121 non-GM maize varieties.

\begin{tabular}{|c|c|c|c|c|c|c|c|c|c|c|}
\hline Protein name & $\begin{array}{c}\text { Spot } \\
\mathbf{n}^{0}\end{array}$ & $\begin{array}{c}\text { MW } \\
\text { (kDa) } \\
\text { theor./ } \\
\text { exp. }\end{array}$ & $\begin{array}{c}\mathrm{pI} \\
\text { theor./ } \\
\text { exp. }\end{array}$ & $\begin{array}{c}\text { NCBI } \\
\text { accession } \\
\text { no. }\end{array}$ & $\begin{array}{c}\mathrm{N}^{\mathbf{o}} \\
\text { of } \\
\text { matched } \\
\text { peptides }\end{array}$ & $\begin{array}{c}\text { Masco } \\
\mathbf{t} \\
\text { score }\end{array}$ & $\begin{array}{c}\text { Fold } \\
\text { of } \\
\text { variatio } \\
\text { n }\end{array}$ & $\begin{array}{l}\text { Cellular } \\
\text { component } \\
\text { GO term }\end{array}$ & $\begin{array}{c}\text { Genome } \\
\text { location } \\
\text { (Chromosome } \\
\text { number) }\end{array}$ & $\begin{array}{l}\text { Molecular } \\
\text { function GO } \\
\text { term }\end{array}$ \\
\hline $\begin{array}{l}\text { Putative cytochrome c } \\
\text { oxidase subunit II PS17 } \\
\text { [Pinus strobus] }\end{array}$ & 56 & $17 / 19$ & $9.6 / 5.2$ & 109892850 & 3 & 67 & 2 & $\begin{array}{l}\text { Chloroplast, } \\
\text { membranes } \\
\text { and } \\
\text { mitochondria }\end{array}$ & $\begin{array}{l}\text { Mitochondrion } \\
\text { and } 9\end{array}$ & $\begin{array}{l}\text { Copper ion } \\
\text { binding and } \\
\text { cytochrome-c } \\
\text { oxidase }\end{array}$ \\
\hline $\begin{array}{l}\text { adenylate kinase }[\text { Zea } \\
\text { mays }]\end{array}$ & 63 & $31.2 / 26$ & $6.8 / 5.0$ & 195611658 & 6 & 277 & 1.5 & Chloroplast & $3 ; 6$ and 8 & $\begin{array}{l}\text { Kinase } \\
\text { transferase and } \\
\text { ATP binding }\end{array}$ \\
\hline $\begin{array}{l}\text { 2-cys peroxiredoxin BAS1 } \\
\text { [Zea mays] }\end{array}$ & 468 & $28.3 / 29$ & $5.8 / 4.2$ & 195626524 & 3 & 152 & OFF & Chloroplast & 4 and 5 & Oxidoreductase \\
\hline $\begin{array}{l}\text { 2-cys peroxiredoxin BAS1 } \\
\text { [Zea mays] }\end{array}$ & 469 & $28.3 / 23$ & $5.8 / 5.0$ & $\underline{195626524}$ & 12 & 326 & OFF & Chloroplast & 4 and 5 & Oxidoreductase \\
\hline $\begin{array}{l}\text { bifunctional 3- } \\
\text { phosphoadenosine 5- } \\
\text { phosphosulfate synthetase } 2 \\
\text { [Zea mays] }\end{array}$ & 478 & $52.5 / 47$ & $8.3 / 6.2$ & 226492878 & 4 & 120 & OFF & $\begin{array}{l}\text { Chloroplast } \\
\text { stroma, } \\
\text { mitochondria } \\
\text { and plasma } \\
\text { membrane }\end{array}$ & 2 & $\begin{array}{l}\text { Sulfate adenylyl } \\
\text { transferase } \\
\text { (ATP) }\end{array}$ \\
\hline $\begin{array}{l}\text { hypothetical protein } \\
\text { SORBIDRAFT_03g012630 } \\
\text { [Sorghum bicolor] }\end{array}$ & 528 & $18.9 / 12$ & $11 / 5.2$ & $\underline{242057187}$ & 2 & 49 & $\mathrm{ON}$ & No annotation & unknown & $\begin{array}{l}\text { Signal } \\
\text { transduction }\end{array}$ \\
\hline $\begin{array}{l}\text { pathogenesis-related } \\
\text { protein } 1 \text { [Zea mays] }\end{array}$ & 529 & $17.1 / 12$ & $5.4 / 5.1$ & 195615416 & 2 & 93 & ON & $\begin{array}{l}\text { Extracellular } \\
\quad \text { region }\end{array}$ & 5 & $\begin{array}{l}\text { Response to } \\
\text { biotic stimulus }\end{array}$ \\
\hline
\end{tabular}




\begin{tabular}{|c|c|c|c|c|c|c|c|c|c|c|}
\hline $\begin{array}{l}\text { chlorophyll a-b binding } \\
\text { protein 6A [Zea mays] }\end{array}$ & 554 & $26.5 / 16$ & $6.2 / 5.2$ & 226503327 & 2 & 164 & ON & Chloroplast & 4 and 5 & $\begin{array}{l}\text { Metal ion } \\
\text { binding }\end{array}$ \\
\hline $\begin{array}{l}\text { thylakoid lumenal } 19 \mathrm{kDa} \\
\text { protein [Zea mays] }\end{array}$ & 557 & $27.4 / 17$ & $5.5 / 4.8$ & 226491484 & 4 & 147 & ON & Chloroplast & 1 & $\begin{array}{l}\text { Calcium ion } \\
\text { binding }\end{array}$ \\
\hline $\begin{array}{l}\text { manganese superoxide } \\
\text { dismutase (SOD-3) (EC } \\
\text { 1.15.1.1) [Zea mays] }\end{array}$ & 561 & $25.6 / 17$ & $7.1 / 6.0$ & 168624 & 6 & 184 & ON & Mitochondria & 6 & $\begin{array}{l}\text { Copper ion } \\
\text { binding and } \\
\text { superoxide } \\
\text { dismutase }\end{array}$ \\
\hline $\begin{array}{l}\text { thylakoid lumenal } 19 \mathrm{kDa} \\
\text { protein [Zea mays] }\end{array}$ & 562 & $27.4 / 17$ & $5.5 / 5.0$ & $\underline{226491484}$ & 6 & 239 & $\mathrm{ON}$ & Chloroplast & 1 & $\begin{array}{l}\text { calcium ion } \\
\text { binding }\end{array}$ \\
\hline $\begin{array}{l}\text { chlorophyll a-b binding } \\
\text { protein 6A [Zea mays] }\end{array}$ & 563 & $26.5 / 18$ & $6.2 / 5.1$ & 226503327 & 2 & 115 & $\mathrm{ON}$ & Chloroplast & 4 and 5 & $\begin{array}{l}\text { Metal ion } \\
\text { binding }\end{array}$ \\
\hline $\begin{array}{l}\text { 14-3-3-like protein A [Zea } \\
\text { mays }]\end{array}$ & 575 & $28.7 / 26$ & $4.9 / 4.7$ & 226510006 & 7 & 348 & $\mathrm{ON}$ & $\begin{array}{l}\text { Cytoplasm } \\
\text { and nucleus }\end{array}$ & 4 & $\begin{array}{l}\text { Cis-acting DNA } \\
\text { regulation }\end{array}$ \\
\hline unknown [Zea mays] & 577 & $37.5 / 27$ & $5.9 / 5.2$ & 194701526 & 4 & 275 & $\mathrm{ON}$ & No annotation & unknown & No annotation \\
\hline $\begin{array}{l}\text { chloroplast fructose-1,6- } \\
\text { bisphosphatase [Oryza } \\
\text { sativa Indica Group] }\end{array}$ & 614 & $39.2 / 50$ & $4.7 / 4.5$ & 165940477 & 6 & 227 & $\mathrm{ON}$ & Chloroplast & $1 ; 8$ and 9 & $\begin{array}{l}\text { phosphoric ester } \\
\text { hydrolase }\end{array}$ \\
\hline $\begin{array}{l}\text { chloroplast fructose-1,6- } \\
\text { bisphosphatase [Oryza } \\
\text { sativa Indica Group] }\end{array}$ & 617 & $39.2 / 50$ & $4.7 / 4.4$ & 165940477 & 4 & 195 & ON & Chloroplast & $1 ; 8$ and 9 & $\begin{array}{l}\text { phosphoric ester } \\
\text { hydrolase }\end{array}$ \\
\hline
\end{tabular}

